\title{
A Performance Case Study of Electronic Governance Implementation in Ghana with WiMAX Technology
}

\author{
E.T. Tchao \\ Department of Electrical \\ Electronic Eng \\ Kwame Nkrumah Univ. \\ of Science and Tech \\ Kumasi, Ghana
}

\author{
W.K. Ofosu \\ Department of Electrical \\ Engineering Technology \\ Penn State Wilkes-Barre \\ USA.
}

\author{
K. Diawuo \\ Department of Electrical \\ Electronic Eng \\ Kwame Nkrumah Univ. \\ of Science and Tech \\ Kumasi, Ghana
}

\begin{abstract}
The arrival of new Information and Communication Technologies (ICTs) has significantly enhanced our capabilities to collect, process and distribute information. As a result of these developments, many developing countries, including Ghana, are realizing the role ICT can play in the Governance sector. The National Information Technology Agency (NITA), which is the body charged in Ghana to provide technological advice and policy frameworks for Electronic Government (e-Government) service delivery, has deployed a pilot e-Government network with WiMAX in parts of Accra and Tema municipality in order to facilitate access to services, including email, web services, data warehousing, government domain name administration, etc. This pilot e-Governance network which is technologically simple is drastically changing the way information is distributed in Ministries, Departments and Agencies (MDAs) in Ghana. This paper discusses the clear, comprehensive layout and network architecture for the e-Government model using WiMAX. Measurement results for traffic generation which were taken from four departments on the e-Government network before the WiMAX deployment is compared with field trial measurement done after WiMAX deployments and results presented.
\end{abstract}

\section{Keywords:}

Information and Communication Technology, Electronic Government, WiMAX, Network Simulation, Field Measurement.

\section{INTRODUCTION}

There are several definitions of e-Government. The World Bank defines e-Government as the use of information technologies by Government agencies that have the ability to transform relations with citizens, businesses, and other arms of government (World Bank, 2005). These technologies can serve a variety of different ends:

- Better delivery of government services to citizens.

- Improved interactions with businesses and industries.

- Citizen empowerment through access of information.

-More efficient government management.

The resulting benefits can be less corruption, increased transparency, greater convenience, revenue growth, and cost reductions [1].

Ghana is a geographically challenged country with about 24 million people scattered throughout remote areas [2]. This presents a formidable barrier to sustainable growth and development. The empowerment of these remote rural areas is crucial for the overall development of the country. Bringing the people in the remote areas to the mainstream of the digital technologies to access and adopt modern technologies is a major concern now in many developing countries [3]. The government of Ghana has therefore charged the National Information Technology Agency (NITA) to implement services which enables the use of ICT tools to transform the work process of government in providing a more efficient, relevant and accessible, cost effective consultative and interactive services to its citizenry [4].

NITA, in order to achieve its aim, plans to use Information and Communication Technology and an affordable last mile broadband solution, i.e., Worldwide Interoperability for Microwave Access (WiMAX), to disseminate information to the remote areas.

WiMAX is a telecommunications technology aimed at providing wireless data over long distances in a variety of ways, from point-to-point links to full mobile cellular type access. It is based on the IEEE 802.16 standard, which is also called WirelessMAN [5]. WiMAX allows a user, for example, to browse the Internet on a laptop computer without physically connecting the laptop to a wall jack at affordable cost. This paper studies the e-Government network currently under deployment in Ghana and presents bandwidth utilization measurements taken from five government departments with the highest traffic generation on the network within a four month period and evaluates if the newly deployed WiMAX network can help deliver a reliable connection to serve requests.

\section{PROPOSED E-GOVERNMENT NETWORK}

The National Information Technology Agency through its mandate seeks to develop and enforce ICT standards to promote interoperability and cost-effective ICT infrastructure and service solutions to promote government policies to the remote part of the country. They also seek to manage shared security infrastructure, networks, servers and services. In line with these objectives, NITA deployed an e-Government model as shown in Figure 1 using a combination of Microwave and Fiber connections to deliver broadband access to MDAs. Due to the high cost involved and the limited range of coverage for the network in the initial nationwide deployment, it later decided to switch to WiMAX technology as shown in Figure 2 to provide a reliable cost effective solution and achieve the main objective of providing last mile broadband solutions to MDAs in the rural areas.. In order 
to implement the e-Governance model to build a well informed and participatory citizenry to enhance good governance, a pilot deployment with WiMAX technology was done in Accra and Tema municipality covering a $55 \mathrm{sq} \mathrm{km}$ to assist the Government of Ghana to generate growth and employment by leveraging ICT and public-private partnerships to develop the IT enabled services industry, and contribute to improved efficiency and transparency of selected government functions through e-government applications as evident by e-Government projects deployed in Nepal, Bangladesh and India[6]|7][8]. Later on, based on the success of the pilot network, the e-Governance project through WiMAX connectivity will be replicated throughout the regional and selected district capitals in the country using 29 WiMAX sites as shown in Figure 2.

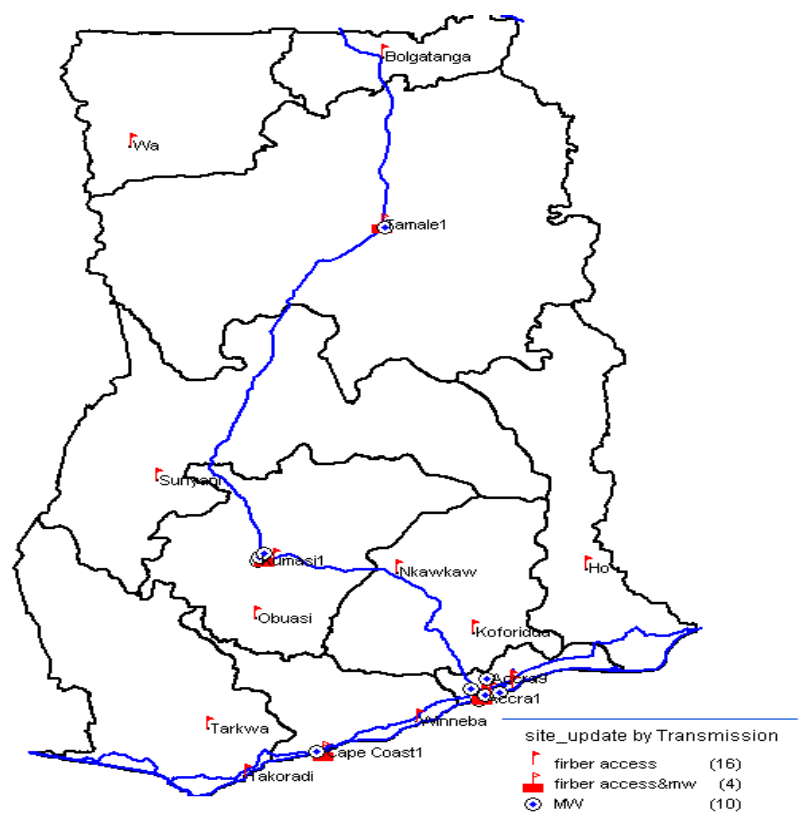

Fig. 1. Initial e-Government Network

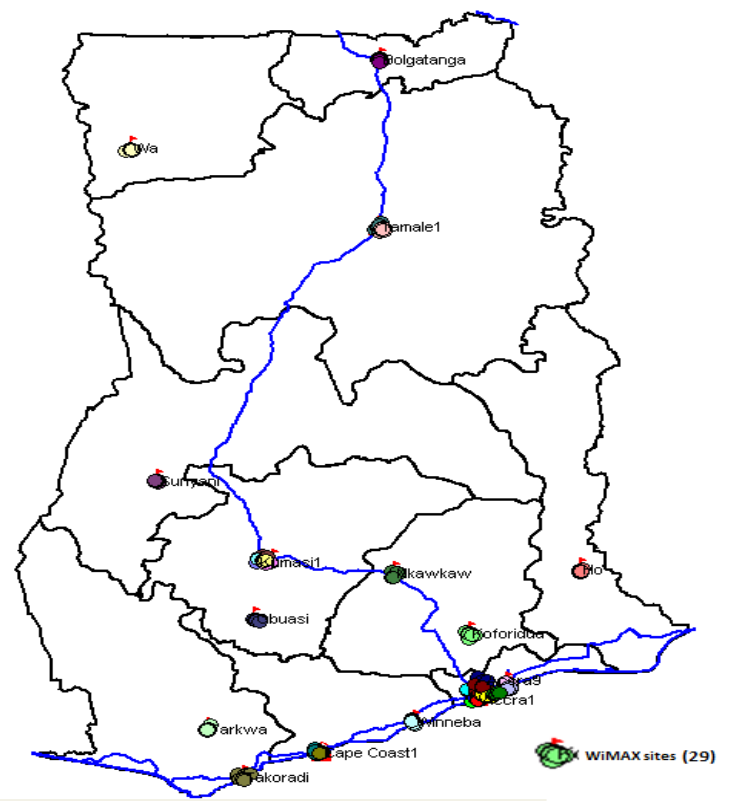

Fig. 2. Proposed nationwide coverage using 29 WiMAX Sites
The proposed network architecture for the e-Government model, as simplified in Figure 3, ensures that even the remote MDAs can access affordable and stable broadband Internet services. This solution includes macro cell and indoor access solutions, and provides adaptive network planning for different scenes. Flat network architecture and distributed base stations have been deployed to ensure fast network establishment and reduce Capex and Opex. This offers an end-to-end WiMAX solution with product lineup including the Terminals, Access, Transmission, and Application Layer equipments.

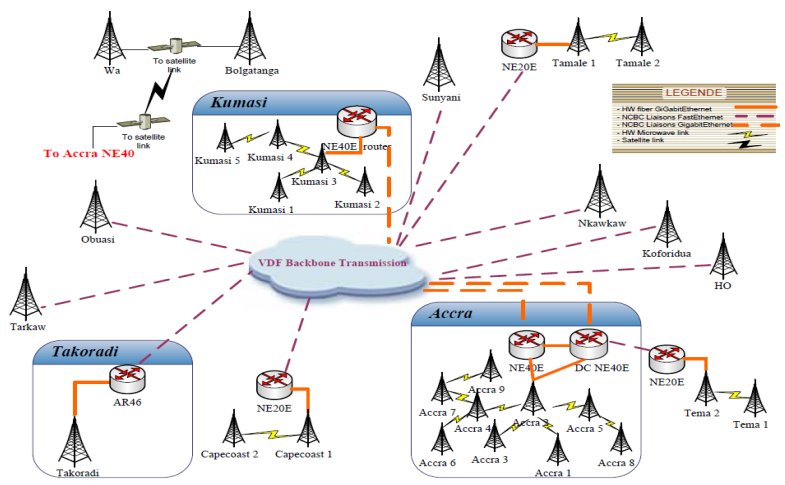

Fig. 3. Proposed Network Architecture for Countrywide WiMAX deployment

The Vodafone backbone transmission is the nerve centre for this network architecture. This backbone transmission will help link the various sub networks which will be located all over the country for efficient network deployment. The network comprises the Accra and Kumasi sub networks which are connected to Vodafone?s backborne transmission by National Communication backborne Company (NCBC) liaisons Gigabit Ethernet (GE) whiles Tamale, Nkawkaw, Obuasi, Koforidua, Takoradi, Ho, Sunyani and Cape Coast networks are linked to Vodafone?s backbone transmission by the NCBC liaisons fast Ethernet. Wa and Bolga are linked by Satellite.

The design incorporates a distinctive distributed Base Station which consists of Base Band Unit (BBU) for indoor installation and Remote Radio Unit (RRU) for wall or pole-mounted. An Advanced Power Module (APM) is used to accommodate BBU for outdoor installation. The use of optical fiber cable to connect $\mathrm{BBU}$ and RRU assures low cable loss and high tolerance to noise. There is also the Access Service Network Gateway (ASN-GW), which is based on a telecom-grade platform with high reliability and full redundancy provision. It serves as a gateway toward Connectivity Service Network (CSN). It can provide a capability of 1000 FA per unit with total up to 600,000 active connections simultaneously. The connectivity project as shown in Figure 4 will provide:

-Data connectivity through Gigabit Ethernet (GE) or fiber to the regional capital, and a point to multi-point WiMAX connection from the regional capital to all the governmental agencies within the region.

- Voice connection through an IP based Private Automated Branch Exchange (PABX)

-Video-conferencing connectivity to connect concurrent videoconferencing sessions even from the remote districts in real time

Mapping for the distribution of Government Agencies and Customer premise Equipments (CPE) in the Municipality as shown in Figure 5 and Figure 6 respectively was done. 


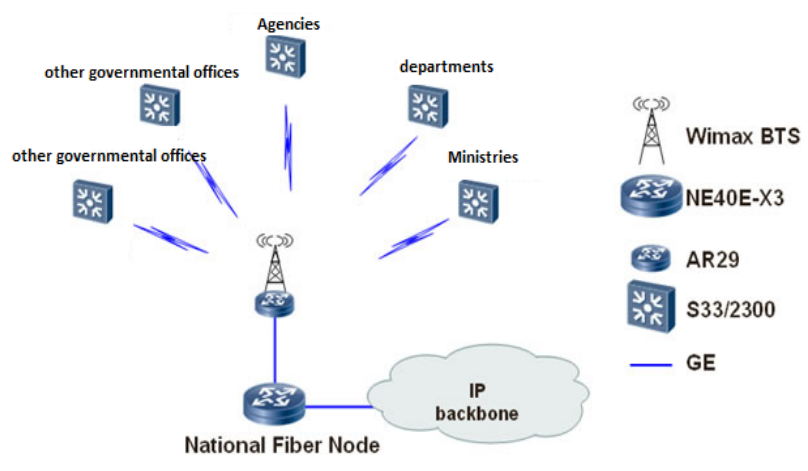

Fig. 4. Layout for a WiMAX base station on the e-Government Network

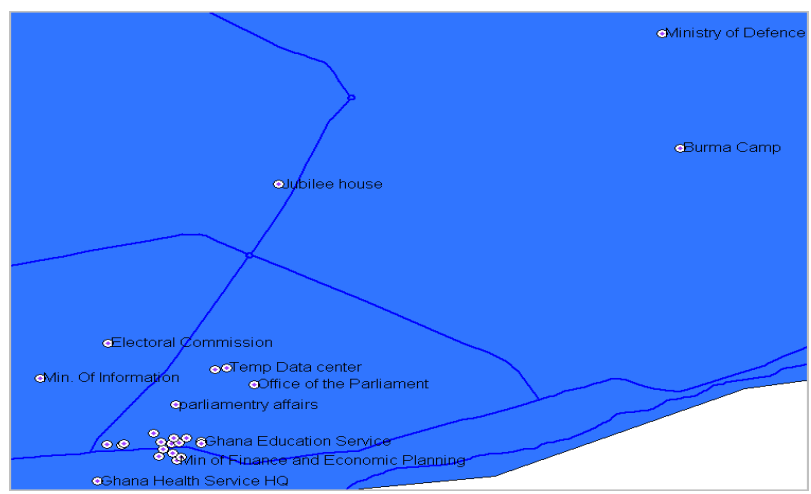

Fig. 5. MDAs in the Pilot Area

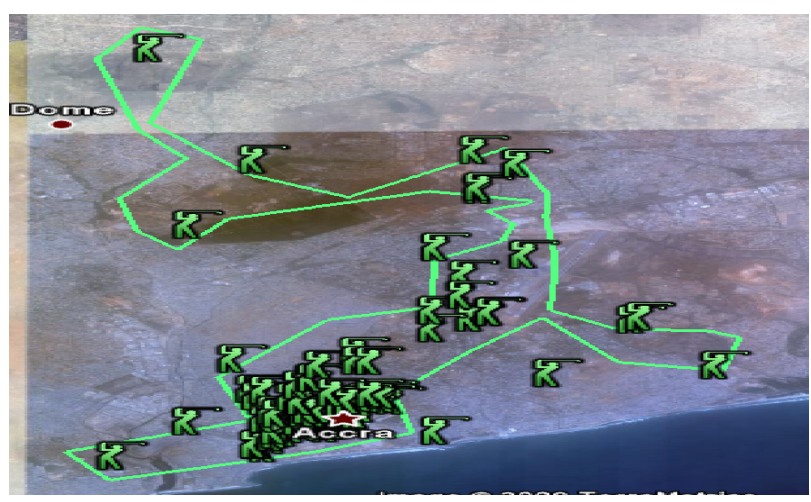

Fig. 6. Distribution of CPEs in the Pilot area

The distribution of governmental agencies on the pilot implementation comprised some key agencies like the Regional coordinating council, the Audit service, Controller and Account General department, parliament house, The Data center, Policy Evaluation department, etc. CPEs in the network comprised fixed users and mobile users who are mostly in the form of police and military patrol vans, IRS tax collectors, etc.

\section{NETWORK SIMULATION}

The final Network radio plan was done with Genex-U-Net. The parameter values used in simulations is given in Table 1.

Initial coverage simulation and WiMAX sites distribution as shown in Figure 7 and Figure 8 respectively indicated that 15 WiMAX sites would be needed to cover the pilot area using an Adaptive $2 \times 2$ MIMO antenna configuration as indicated by the points in Figure 8.
Table 1. Simulation Parameters

\begin{tabular}{|l|l|}
\hline Resource frequency & $2.5-2.53 \mathrm{GHz}$ \\
\hline Channel Bandwidth & $10 \mathrm{MHz}$ \\
\hline Fast Fourier Transform (FFT) Size & 1024 \\
\hline Subcarrier spacing & $10.93 \mathrm{kHz}$ \\
\hline Useful symbol time & $91.4 \mu \mathrm{s}$ \\
\hline Guard time & $11.4 \mu \mathrm{s}$ \\
\hline OFDMA symbol time & $102.8 \mu \mathrm{s}$ \\
\hline Modulation & QPSK, 16-QAM, \\
& $64-\mathrm{QAM}$ \\
\hline Antenna frequency Range & $2.3-2.7 \mathrm{GHz}$ \\
\hline VSWR & $\leq 1.5$ \\
\hline Input Impedance & $50 \Omega$ \\
\hline Gain & $18 \mathrm{dBi}$ \\
\hline Horizontal Beamwidth & $(3 \mathrm{~dB}) 60^{\circ}$ \\
\hline Vertical Beamwidth & $(3 \mathrm{~dB}) 7^{\circ}$ \\
\hline Electrical downtilt & $2^{\circ}$ \\
\hline Maximum power & $250 \mathrm{~W}$ \\
\hline Antenna height & $38 \mathrm{~m}$ \\
\hline
\end{tabular}

Table 2. Coverage Range Simulation results for WiMAX CPE in the network

\begin{tabular}{|l|l|l|}
\hline CPE Type & Morphology & Coverage range $(\mathrm{Km})$ \\
\hline \multirow{4}{*}{ Indoor } & Dense Urban & $0.6-0.7$ \\
\cline { 2 - 3 } & Urban & $1.0-1.5$ \\
\cline { 2 - 3 } & Sub-Urban & $2.3-2.5$ \\
\cline { 2 - 3 } & Rural & $4.8-5.5$ \\
\hline \multirow{4}{*}{ Outdoor } & Dense Urban & $3.8-4.5$ \\
\cline { 2 - 3 } & Urban & $4.6-5.2$ \\
\cline { 2 - 3 } & Sub-Urban & $7.8-9.3$ \\
\cline { 2 - 3 } & Rural & $13.5-18.5$ \\
\hline
\end{tabular}

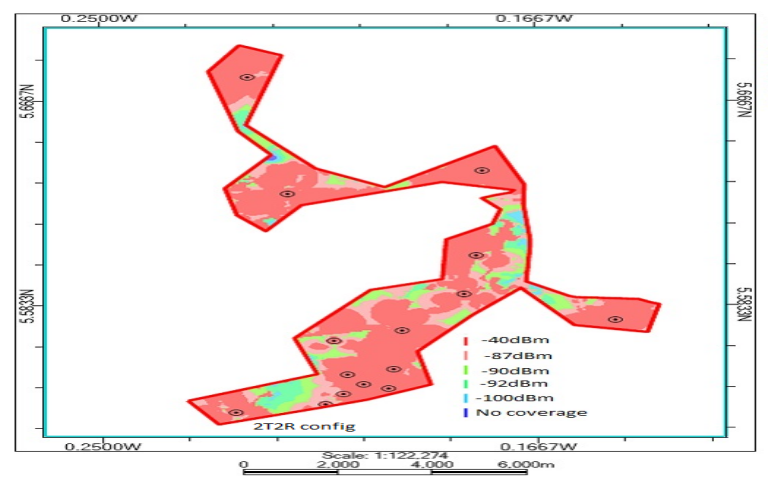

Fig. 7. Initial Coverage simulation using Adaptive $2 \times 2$ MIMO configurationa

Adaptive $4 \times 4$ MIMO antenna configurations simulations in [9] gives a $3 \mathrm{~dB}$ increase in downlink/uplink coverage and higher throughput which reduces the number of base station sites to eleven decreasing the total cost of deployment.

\subsection{Measurement Setup}

Traffic from four departments in the pilot area, namely the Regional Coordinating Council, datacenter, Audit service and Brand Ghana, within a four months period was measured prior to deploying the WiMAX network. The results of the measurements are shown in Figures 9-12

After the WiMAX network was deployed, a trial measurement was carried out in several parts of Accra and Tema, where these traffic measurements for the four departments were taken. This enabled us to test WiMAX technology to see if it could provide last mile broadband solution to the rural areas. The trial was also aimed at testing the technology to see if it could serve existing 


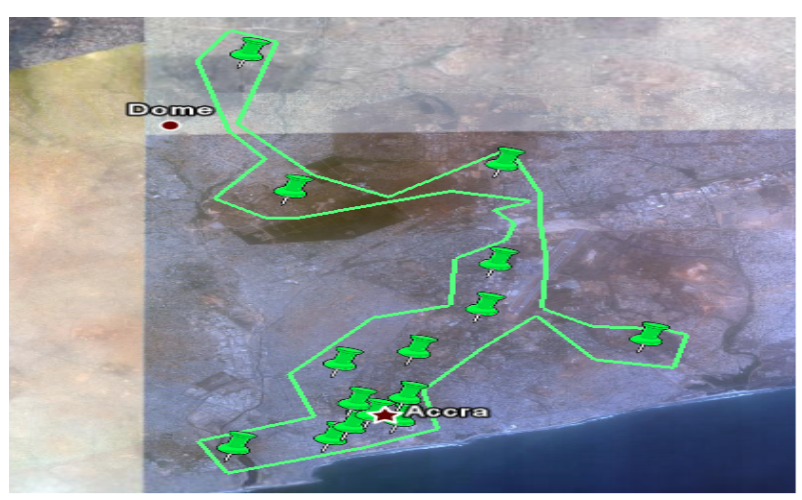

Fig. 8. Initial distributions of WiMAX sites based on coverage simulation

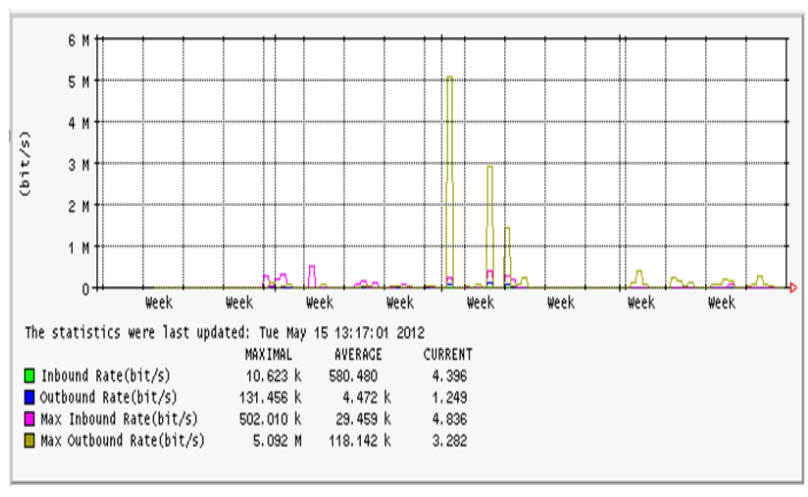

Fig. 9. Traffic generation from the Regional Coordinating Council

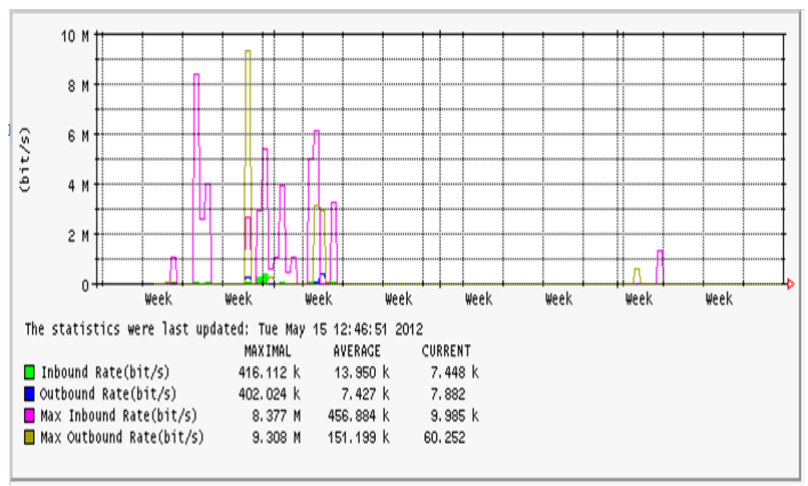

Fig. 10. Traffic generation from the Datacenter

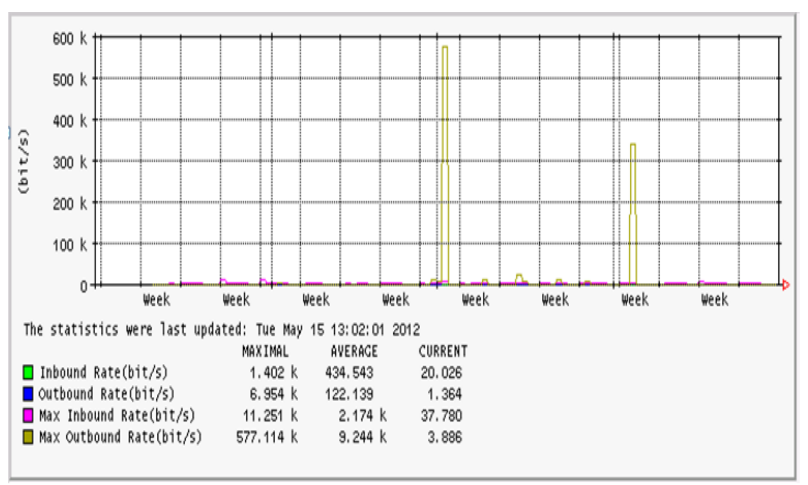

Fig. 11. Traffic generation from the Audit service

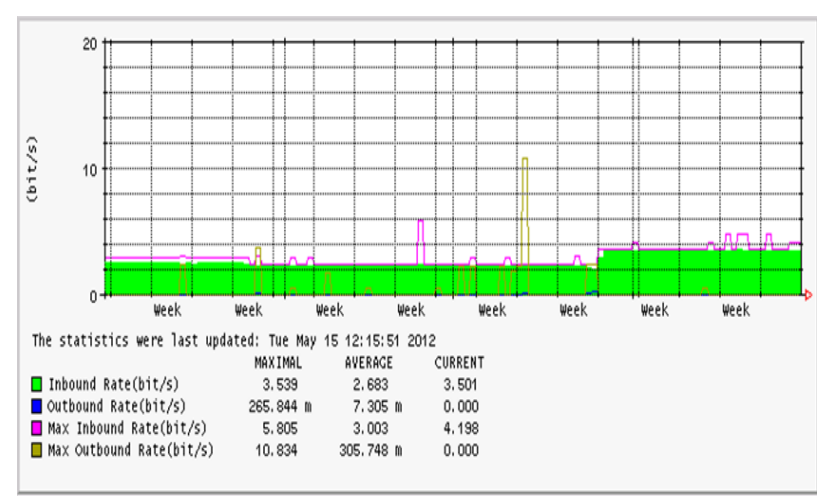

Fig. 12. Traffic generation from Brand Ghana

traffic as measured from the four highest traffic generating agencies in the network area. Table 3 summarizes the measured average throughput per sector for four WiMAX sites which served the four Agencies.

Table 3. Measured average throughput per sector

\begin{tabular}{|c|c|c|c|c|}
\hline \multirow[t]{2}{*}{ Name } & \multirow[t]{2}{*}{ Sector } & \multirow{2}{*}{$\begin{array}{l}\text { Height } \\
\text { of } \\
\text { Trans- } \\
\text { mit- } \\
\text { ter(m) }\end{array}$} & \multicolumn{2}{|c|}{$\begin{array}{l}\text { WiMAX Carrier Average } \\
\text { Throughput per sector }\end{array}$} \\
\hline & & & $\begin{array}{l}\text { DL } \\
\text { Mbps }\end{array}$ & $\begin{array}{l}\mathrm{UL} \\
\text { Mbps }\end{array}$ \\
\hline \multirow[t]{3}{*}{ Site1 } & Sector 1 & 38 & 6.09 & 2.81 \\
\hline & Sector 2 & 38 & 4.91 & 0.651 \\
\hline & Sector 3 & 38 & 4.99 & 2.09 \\
\hline \multirow[t]{3}{*}{ Site 2} & Sector 1 & 38 & 3.84 & 1.08 \\
\hline & Sector 2 & 38 & 9.62 & 0.825 \\
\hline & Sector 3 & 38 & 4.75 & 0.846 \\
\hline \multirow[t]{3}{*}{ Site 3} & Sector 1 & 38 & 3.31 & 1.32 \\
\hline & Sector 2 & 38 & 4.81 & 2.92 \\
\hline & Sector 3 & 38 & 5.17 & 3.68 \\
\hline \multirow[t]{3}{*}{ Site 4} & Sector 1 & 38 & 3.28 & 1.45 \\
\hline & Sector 2 & 38 & 2.94 & 0.26 \\
\hline & Sector 3 & 38 & 4.66 & 2.72 \\
\hline
\end{tabular}

During the field trial measurement stage, there were about 535 active indoor and outdoor CPEs on the pilot network. A file size of $10 \mathrm{Mb}$ was first downloaded from the remote server and later the same file size was uploaded unto the server. The Regional coordinating council, the Datacenter, Audit service and Brand Ghana are located in sites 1,2, 3 and 4 respectively.

\subsection{Discussion Of Results}

From the initial traffic measurements as summarized in Figures 9-12, it was realized that the highest traffic generation came from the data center with a maximum outbound traffic of $9.308 \mathrm{Mbps}$, Regional coordinating council with 5.092Mbps and brand Ghana having the least maximum outbound traffic of $10.834 \mathrm{bps}$. The measured throughput of $1 \mathrm{Mpbs}$ which was obtained from about $2.5 \mathrm{~km}$ away from the base station is enough to support most broadband applications as specified in [10]. The minimum measured average throughput per sector of $300 \mathrm{kbps}$ at about a distance of $4 \mathrm{~km}$ away from the base station is enough to support most web browsing and webservice applications. The maximum measured average throughput per sector of $9.62 \mathrm{Mbps}$ in site 2 is enough to cater for the traffic of the data center. The range of about $13.5-18.5 \mathrm{~km}$ for rural areas as indicated by the coverage range simulations for the network in Table 2, will be enough to provide broadband access to MDAs in the rural areas. 


\subsection{Conclusion}

A look at other countries that have implemented e-Government successfully prove that in such countries there have been wellauthored strategies and implementation plans. Examples of countries that have taken this approach include Singapore which has an e-Government Action Plan (eGAP) [11], Tanzania and Mozambique which have put in place e-Government implementation strategies and roadmaps [12]. Based on the success of the pilot network in Ghana, a nationwide deployment of WiMAX network has begun using the documented strategies and implementation plans for the pilot network to implement applications like:

-Integrated Payroll and Personnel Database for government workers by the controller and Accountant General?s department

- Integrated Financial Management Information System by the Ministry of Finance and Economic planning

—online TAX returns by the Internal Revenue Service

-Biometric Passport applications by the Ghana Immigration Service

-National Identification application processing by the National Identification Authority.

With the WiMAX network promising high bandwidth gains and longer distance of coverage for the e-Government network, it is highly expected that WiMAX will help remove the geographic barrier which retards rural development and improve dissemination of Government policies to the rural areas in Ghana.

\section{REFERENCES}

[1] U. Dalal K. Chaudhari and R. Jha. E-governance in rural india: Need of broadband connectivity using wireless technology. Wireless Engineering and Technology, Vol. 2:pp. 212-220, 2011.

[2] Ghana A country profile. online:http.//www.accraexpat.com. accessed on 2/05/2013.
[3] H. S Kumara. Ict driven e-governance public service delivery mechanism in rural areas: A case of rural digital services (nemmadi) project in karnataka, india. Journal of Computing and ICT Research, Vol. 4, Issue 2:pp. 37-45.

[4] Medium-term national development policy framework: Ghana Shared Growth And Development Agenda (GSGDA), 2010-2013, policy framework final draft, february, 2011.

[5] IEEE 802.16. IEEE standard for local and metropolitan area networks, part 16: Air interface for fixed broadband wireless access systems, 2004.

[6] Santosh Shingare, Pratik Shinde, Depankar Sarkar, Priya Uttarwar, and Rashmi Dusane. E-governance at village level administration in rural india. In World conference on Agricultural Information and IT, IAALD AFITA 2008.

[7] G.Z. Islam. Developing a model of e-governance for urban and rural areas of bangladesh,computer and information technology. In 11th International Conference on Computer and Information Technology ICCIT 2008., pages page 587 - 592, 24-27 Dec. 2008.

[8] E-Governance - ts Prospectives, Opportunities And Threats In Nepal. 123HelpMe.com. 03 May 2013.

[9] E.T.Tchao, W.K. Ofosu, and K. Diawuo. Radio planning ad field trial measurement for a $4 \mathrm{~g}$ wimax network in a subsaharan africa environment. In IEEE Wireless Telecommunications symposium, Phoenix,Arizona, 17-19th April 2013.

[10] Broadband Speed Guide . www.fcc.gov/guides/broadbandspeed-guide. Accessed online on 7th January, 2013.

[11] The Singapore E-government Action Plan:United Nations publication, . online:http://unpan1.un.org/intradoc/groups /public/documents/UNPAN002999.pdf . Accessed 2/05/2013.

[12] Bwalya K. J. and M. Healy. Harnessing e-Government Adoption in the SADC Region: a Conceptual Underpinning. Electronic Journal of e-Government, Volume 8:pp 23 $-32,2010$. 